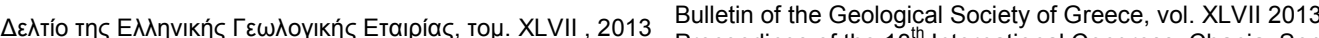
XIV, 2013 Proceedings of the $13^{\text {th }}$ International Congress, Chania Sept.

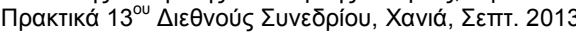
2013

\title{
CONSTRAINTS ON THE LOCATION OF THE 2008, $\mathrm{M}_{\mathrm{w}} 6.4$ ACHAIA-ILIA EARTHQUAKE FAULT FROM STRONG MOTION DATA
}

\author{
Roumelioti Z. ${ }^{1}$, Theodoulidis N. ${ }^{2}$ and Bouchon M. $^{3}$ \\ ${ }^{I}$ Research Unit of Soil Dynamics and Geotechnical Earthquake Engineering, Department of Civil \\ Engineering, P.O.Box 424, 54124 Thessaloniki, Greece, zroum@auth.gr \\ ${ }^{2}$ Institute of Engineering Seismology and Earthquake Engineering (ITSAK-EPPO), P.O. Box 53, \\ 55102 Thessaloniki,Greece,ntheo@itsak.gr \\ ${ }^{3}$ Université Joseph Fourier, BP 53, 38041 Grenoble,France, bouchon@ujf-grenoble.fr
}

\begin{abstract}
The June 2008, $M_{w} 6.4$ Achaia-Ilia earthquake was the first recorded dextral strikeslip event of considerable magnitude in western Peloponnese, which, nevertheless, could not be related to any of the known/mapped structures at the ground surface. Published locations of the mainshock focus by various agencies/researchers differ by as much as $6 \mathrm{~km}$ and $16 \mathrm{~km}$ in the horizontal and vertical dimensions, respectively, making even more difficult the accurate siting of the seismogenic fault. However, the 2008 earthquake provided a valuable set of near-fault strong motion data, which could shed some light on the problem of accurately locating the earthquake source. To this end, we use the discrete wavenumber method to forward model the strong ground motion records at three stations, located close to the prolongation of the 2008 strike. We test different locations and lengths for the ruptured plane and compare synthetic polarities and amplitudes of the first strong $S$-wave pulse to actual data. We conclude that the line of maximum moment release (our fault models are vertical planes) during the 2008 earthquake is located to the east of the imaginary line connecting stations PAT2 and AMAA and to the west of station PYR1.
\end{abstract}

Key words: Andravida, Western Greece, acceleration.

\section{Пєрí $\eta \psi \eta$}

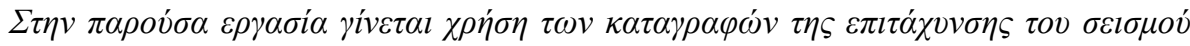

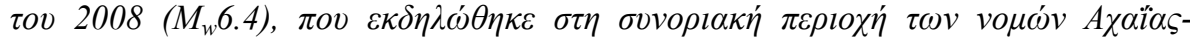

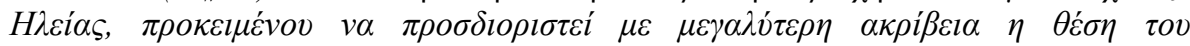

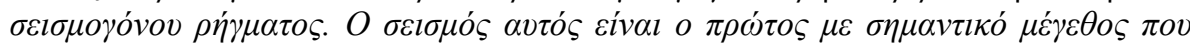

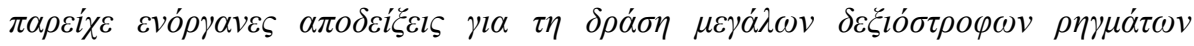

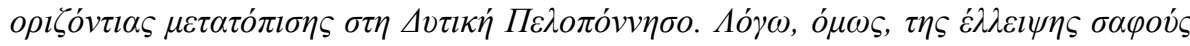

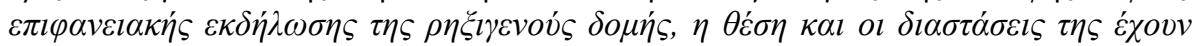

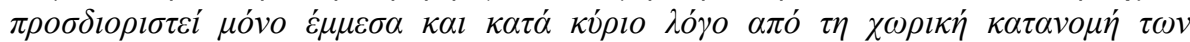

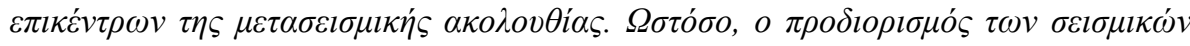

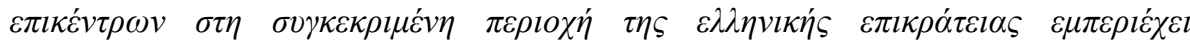

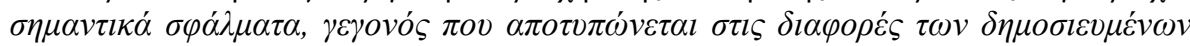

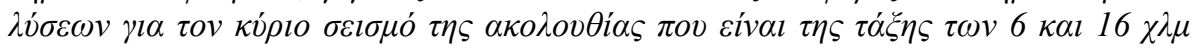

XLVII, No 3 - 1231 


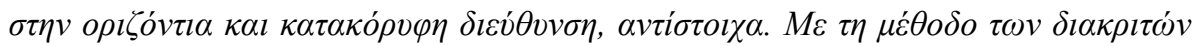

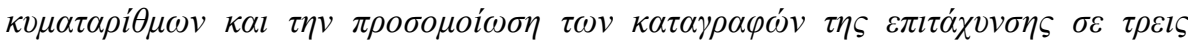

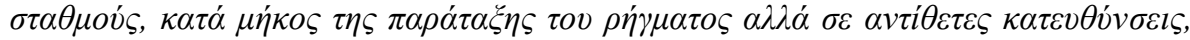

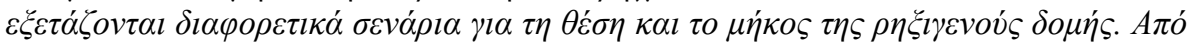

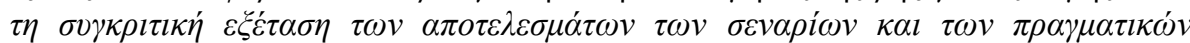

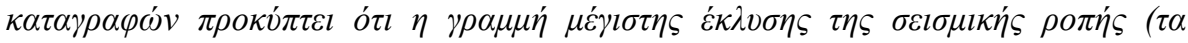

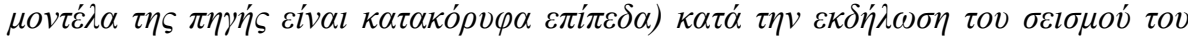

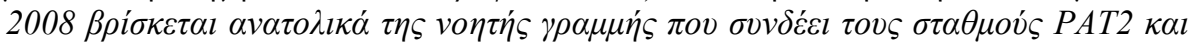

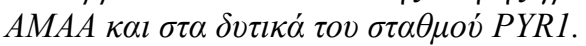

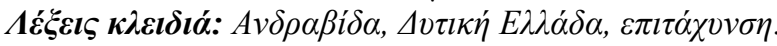

\section{Introduction}

On June 08, 2008 an $\mathrm{M}_{\mathrm{w}} 6.4$ earthquake shook the Achaia-Ilia prefectures in NW Peloponnese (Greece). This event attracted the interest of many researchers not only because of its impact (two deaths, hundreds injured, small to significant damage to masonries and life-lines; e.g. Margaris et al., 2010) but also because it was the first recorded dextral strike-slip event of considerable magnitude in this part of Greece. Shortly after the earthquake, it was concluded that the rupture did not reach the surface and the seismogenic fault could not be related to any of the known, mapped structures (Koukouvelas et al., 2010).

The 2008 Achaia-Ilia earthquake has been the subject of numerous scientific studies (e.g. Ganas et al., 2009; Gallovic et al., 2009; Feng et al., 2010; Konstantinou et al., 2010, 2011; Margaris et al., 2010; Papadopoulos et al., 2010; Zahradnik et al., 2010). Most of the aforementioned studies tend to converge on the idea that a deep, newly formed right lateral strike-slip fault zone has started taking the deformation in NW Peloponnese in a way similar to the Cephalonia transform fault. A different opinion is given by Konstantinou et al. (2011), who found that the 2008 seismogenic fault was significantly different in orientation (by 68०) with respect to the maximum principal stress axis in NW Peloponnese. This finding argues against the birth of a new fault and thus Konstantinou et al. (2011) relate the 2008 event to a pre-existing structure that was reactivated in an over-pressured lower crust. The most recent, pertinent to the 2008 earthquake, study, which performs a crustal anisotropy analysis (Giannopoulos et al. 2012) favors the latter opinion.

Scientific controversy is not restricted to the geological age of the ruptured fault; it also extends to routine earthquake locations. A characteristic example is the comparison of the absolute locations of the aftershock sequence of the 2008 earthquake in two independent studies i.e. Gallovic et al. (2009) and Konstantinou et al. (2010) (Figure 1). Although both research teams performed relocation techniques, the independently computed aftershock clusters appear clearly separated in space with a mean shift between clusters of the order of $2 \mathrm{~km}$. Of course, such a difference lies within the expected uncertainties in earthquake locations, which are quite large in this part of Greece due both to the complicated earth structure and the lack of seismological stations to the WNW (i.e. in the Ionian Sea). Differences in mainshock location solutions are not smaller. In fact, published locations differ by as much as $6 \mathrm{~km}$ in the horizontal direction and $16 \mathrm{~km}$ in the vertical.

Since the 2008 earthquake appears to significantly alter/complement the pre-existing scientific knowledge of the on-going seismotectonic processes in NW Peloponnese, its source characteristics are of great importance. In the present study we put additional constraints on the location of the 2008 seismogenic source and its dimensions by exploiting information carried in near-fault strong ground motion recordings. The discrete wavenumber method is used to simulate acceleration waveforms recorded in the vicinity of the 2008 earthquake. We test several models incorporating different locations and lengths of the seismogenic fault. The optimum location is the one that reproduces the recorded low-frequency signal polarities and amplitudes of strong ground motion.

XLVII. No $3-1232$ 


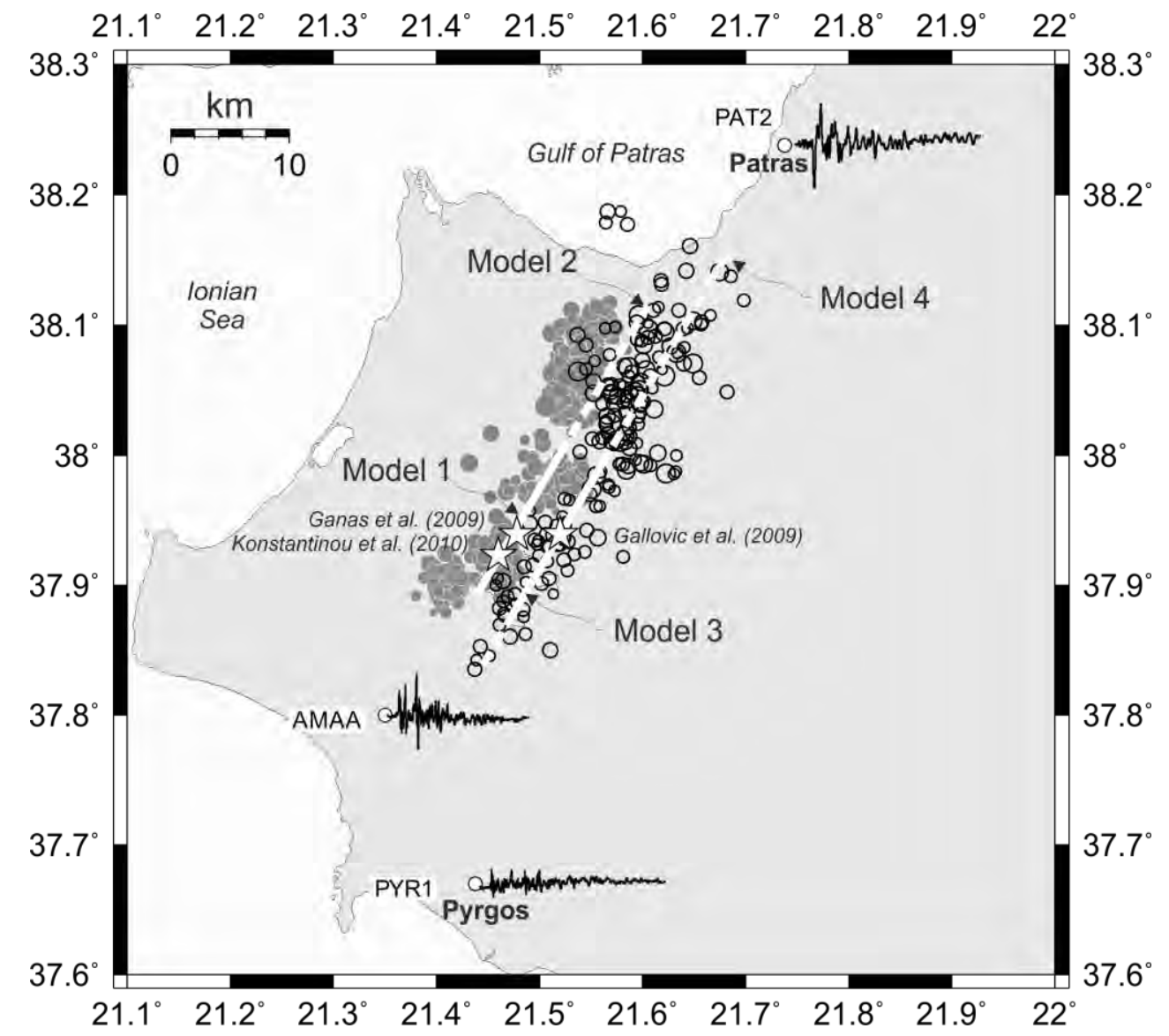

Figure 1 - Regional map showing relocated epicenters of the 2008 Achaia-Ilia earthquake (star symbols) suggested by different researchers and aftershock locations as computed by

Konstantinou et al. (2010; dark grey solid circles) and Gallovic et al. (2009; open black circles). The locations and acceleration waveforms (one of the horizontal components) of stations PAT2, AMAA and PYR1 are also shown. Thick white lines, continuous and dashed, indicate the surface projections of the four tested source models.

\section{Strong Ground Motion Data}

The 2008 earthquake was recorded by 27 strong motion stations (Margaris et al., 2010), nine of which were located at relatively close distance $(<50 \mathrm{~km})$ from the seismic source. Among the latter, six stations are clustered in the city of Patras. In the present work, we selectively deal with the recordings at stations PAT2 (among the six stations installed in Patras), AMAA and PYR1, which are located along the line of the rupture, at opposite directions with respect to the 2008 epicenter (Figure 1). Information on the strong motion stations used herein is provided in Table 1.

Prior to any processing, data were carefully checked for polarity reversals. Original acceleration records were integrated to velocity without applying any filtering in order to preserve all information at low frequencies. The velocity waveforms at the three examined stations, PAT2, AMAA and PYR1, are plotted in Figure 2. Transverse component at station PAT2 appears quite simple with one dominant low-frequency pulse, while corresponding recordings at stations AMAA and PYR1 show larger complexity with at least three distinct pulses. At a first glance, one could conclude rupture directivity toward the north, where PAT2 station is located. 
Table 1 - Information on the three accelerograph stations used in this study. Orientations

(LVT, modified LVT as used in SMA-1) have been converted to XYZ for reasons of uniformity (positive polarity i.e. positive output for positive acceleration).

\begin{tabular}{ccccccccc}
\hline $\begin{array}{c}\text { Station } \\
\text { Code }\end{array}$ & Location & $\begin{array}{c}\mathbf{L a t}^{\circ} \\
(\mathbf{N})\end{array}$ & $\begin{array}{c}\text { Lon }^{\circ} \\
(\mathbf{E})\end{array}$ & $\begin{array}{c}\mathbf{A z} \\
(\mathbf{X})\end{array}$ & $\begin{array}{c}\text { PHA } \\
(\mathbf{g})\end{array}$ & $\begin{array}{c}\text { Az } \\
(\mathbf{Y})\end{array}$ & $\begin{array}{c}\text { PHA } \\
(\mathbf{g})\end{array}$ & Operator* $^{*}$ \\
AMAA & $\begin{array}{c}\text { Amaliada } \\
\text { Patra }-\end{array}$ & 37.795 & 21.350 & $280^{* *}$ & 0.244 & $190^{* *}$ & 0.241 & NOA \\
PAT2 & $\begin{array}{c}\text { Agios } \\
\text { Dimitrios }\end{array}$ & 38.238 & 21.738 & 15 & 0.091 & 285 & 0.100 & ITSAK \\
PYR1 & Pyrgos & 37.670 & 21.438 & 80 & 0.085 & 350 & 0.056 & ITSAK \\
\hline
\end{tabular}

* NOA: National Observatory of Athens; ITSAK: Institute of Engineering Seismology and Earthquake Engineering.

** Revised orientation of AMAA instrument was provided by I. Kalogeras of NOA (personal communication).

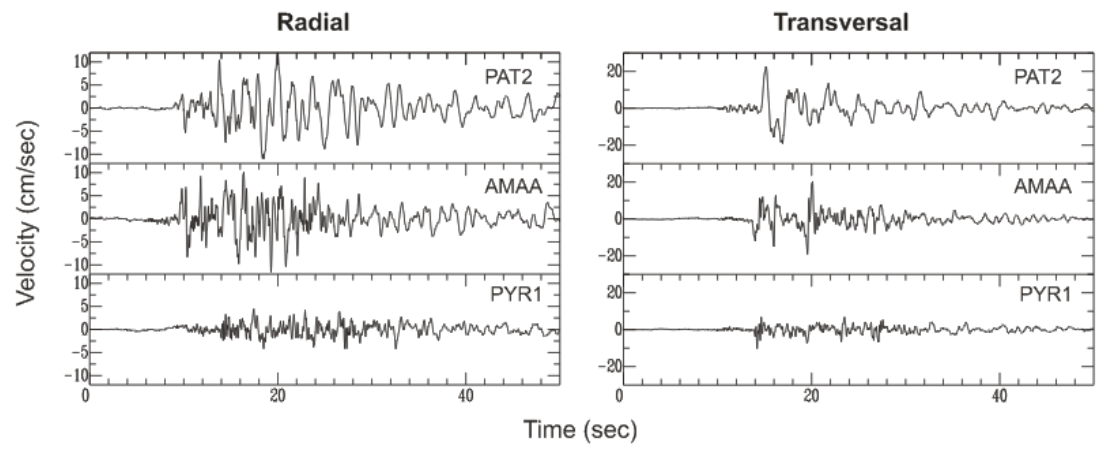

Figure 2 - Velocity records at the two horizontal components of stations PAT2, AMAA and PYR1. Originally recorded accelerograms have been integrated to velocities and rotated to obtain the fault-parallel (Radial; left) and fault-normal (Transversal; right) components of ground motion.

\section{Investigating Different Source Scenarios}

\subsection{Method}

The method used to simulate observed ground motion at stations PAT2, AMAA and PYR1 is the Discrete Wavenumber Number (DWN) originally introduced by Bouchon and Aki (1977) and extensively reviewed in Bouchon (2003). For reasons of space economy, we do not include a description of the DWN herein and, thus, the reader is referred to the aforementioned studies.

\subsection{Application and Results}

We tested four different fault models, which were defined based on the two different pictures of the relocated 2008 sequence, as suggested by Gallovic et al. (2009) and Konstantinou et al. (2010). The surface projections of the four fault models (all of them considered to be vertical and with a strike of $211^{\circ}$ ) are shown in Figure 1. Apart from different location, we also investigated different fault lengths, $L$, i.e. by including or not the northernmost cluster of afteshocks, which appears to deviate from the strike suggested by the moment tensor of the 2008 mainshock. Details on the geometry of the tested models are summarized in Table 2.

In all our applications rupture velocity, $V_{r}$, was considered equal to $3.0 \mathrm{~km} / \mathrm{sec}$, i.e. close to $80 \%$ of the S-wave velocity at the depth of the hypocentre and identical to the value used in Gallovic et al. 
(2009). Dislocation rise time was taken to be equal to $10 \%$ of the total rupture duration (Heaton, 1990), $T$, where $T=L / V_{r}$. Average slip varied depending on the dimensions of each fault model, although in all cases total slip (mean slip $\times$ fault surface) was constant.

Table 2 - Parameters of the four fault models (Figure 1) tested in the present study.

\begin{tabular}{|c|c|c|c|c|}
\hline & MODEL1 & MODEL2 & MODEL3 & MODEL4 \\
\hline \multirow{2}{*}{ Location } & $37.89 \mathrm{~N}-21.44 \mathrm{E}$ & $37.89 \mathrm{~N}-21.44 \mathrm{E}$ & $37.87 \mathrm{~N}-21.47 \mathrm{E}$ & $37.84 \mathrm{~N}-21.45 \mathrm{E}$ \\
\hline & $38.01 \mathrm{~N}-21.53 \mathrm{E}$ & $38.12 \mathrm{~N}-21.62 \mathrm{E}$ & $37.99 \mathrm{~N}-21.56 \mathrm{E}$ & $38.16 \mathrm{~N}-21.70 \mathrm{E}$ \\
\hline Length $(\mathrm{km})$ & 16 & 30 & 16 & 42 \\
\hline $\begin{array}{l}\text { Depth of top } \\
\text { of fault }(\mathrm{km})\end{array}$ & 15 & 15 & 15 & 15 \\
\hline $\begin{array}{l}\text { Depth of } \\
\text { bottom of } \\
\text { fault }(\mathrm{km})\end{array}$ & 30 & 30 & 30 & 30 \\
\hline $\begin{array}{c}\text { No of } \\
\text { subfaults } \\
\text { (strike } \times \text { dip) }\end{array}$ & $16 \times 15$ & $30 \times 15$ & $16 \times 15$ & $42 \times 15$ \\
\hline Focal Depth & 24 & 24 & 24 & 24 \\
\hline $\begin{array}{l}\text { Subfault of } \\
\text { hypocentre } \\
\text { along strike }\end{array}$ & 11 & 25 & 9 & 29 \\
\hline $\begin{array}{l}\text { Rupture } \\
\text { Velocity } \\
(\mathrm{km} / \mathrm{sec})\end{array}$ & 3.0 & 3.0 & 3.0 & 3.0 \\
\hline $\begin{array}{l}\text { Rise time } \\
\quad(\mathrm{sec})\end{array}$ & 0.5 & 1.0 & 0.5 & 1.4 \\
\hline
\end{tabular}

In Figures 3, 4 and 5, we present the results from all four tested models and for the two horizontal components of ground velocity at stations PAT2, AMAA and PYR1, respectively. The main conclusions drawn from the comparative study of these Figures are the following:

- Model 1 is the only one among the four tested models that places stations PAT2 on the western, northward moving part of the fault. The result is that the synthetic S-wave pulse in the radial component (Figure $3 b$ ) is negative, i.e. of reversed polarity compared to observations. Thus, the true location of the seismogenic fault is to the east of model 1.

- Overall, amplitude and shape of the S-wave pulses at the three examined stations are better fitted with models 1 and 3. Models 2 and 4 include larger rise time (because of the proportionality of this quantity with the rupture length, which is quite larger in models 2 and 4) and result in longer period S-wave pulses.

- Duration of observed records seem to require rupture length greater than $16 \mathrm{~km}$ assumed in models 1 and 3. However, larger length should then be combined with values of rise time much smaller than those predicted by empirical equations (Heaton, 1990), i.e. the 2008 would be unusually fast. In fact, Feng et al. (2010) concluded that the studied event was unusually strong in terms of high-frequency energy.

- Although the transversal component is overall well fitted by models 1 and 3 , the radial component shows poorer fit. Among the many factors that affect the amplitude of this component, is the distance of the station from the fault on the perpendicular to the strike direction. For example, the radial component of PYR1 (Figure 5b) in model 3 is overpredicted and this implies that the station should be closer to the true fault (closer to nodal) than it is in the specific model. The opposite is observed in Figure 3b, i.e. at the radial 
component of PAT2. Assumed location of PAT2 relative to the fault of model 3 is obviously too small, resulting to very low amplitudes in the synthetic waveforms.

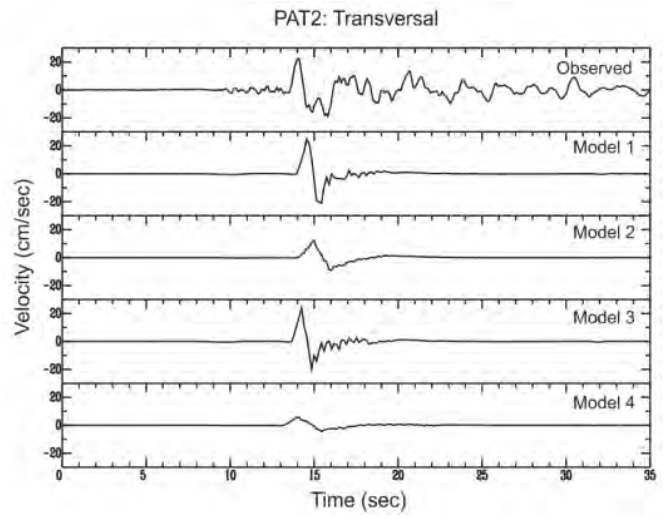

(a)

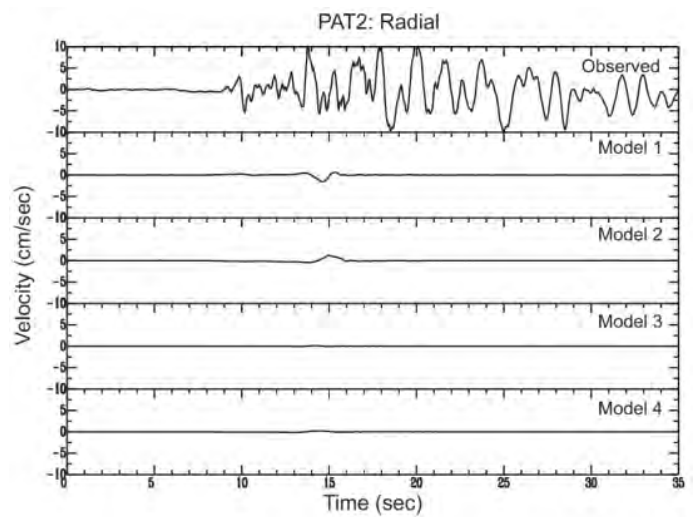

(b)

Figure 3 - a) Comparison of observed velocity at the transversal component of station PAT2 with synthetic waveforms based on four different fault models (Figure1, Table 2). All waveforms are high-pass filtered at $0.08 \mathrm{~Hz}$. b) Corresponding results for the radial component at station PAT2.

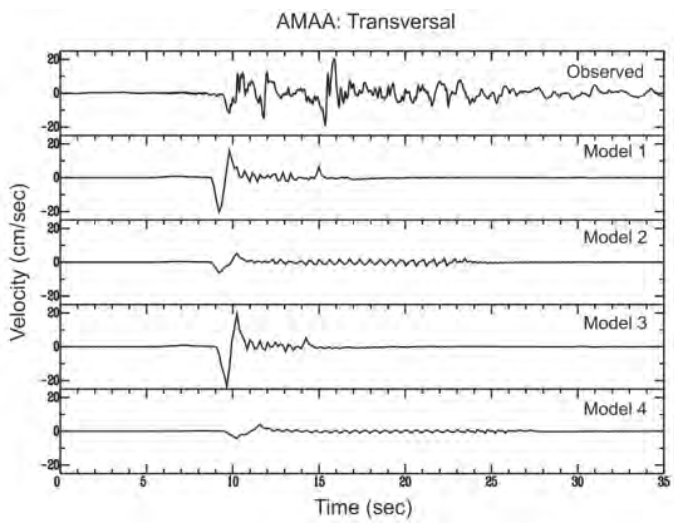

(a)

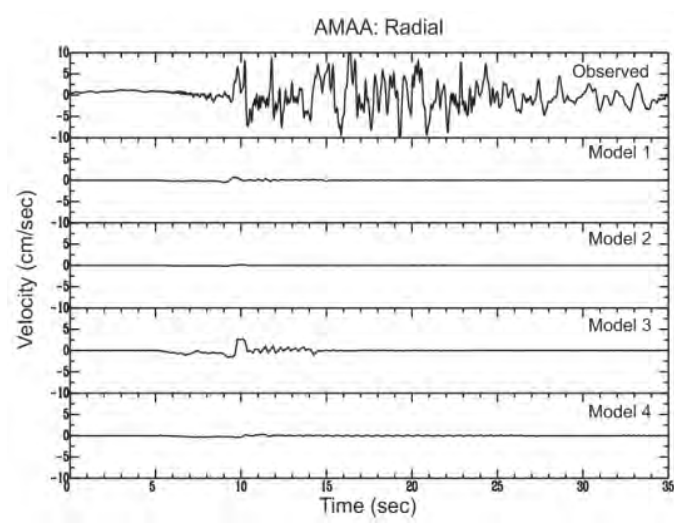

(b)

Figure 4 - a) Comparison of observed velocity at the transversal component of station AMAA with synthetic waveforms based on four different fault models (Figure1, Table 2). All waveforms are high-pass filtered at $0.08 \mathrm{~Hz}$. b) Corresponding results for the radial component at station AMAA.

Keeping in mind the aforementioned conclusions, we tested several other locations of the fault model and achieved, by trial and error, the best overall match between synthetic and observed amplitudes in all three components of ground motion. The most important constraint comes from the amplitude of the initial S-wave pulse in the radial components of the three examined stations. To optimally reproduce strong motion amplitudes at all three stations, a shift of our fault model further to the east is required i.e. further away from stations PAT2 and AMAA and closer to station PYR1. Our best synthetics are compared to observed acceleration time histories in Figure 6. We should once more note that we focus on reproducing the rough shape and amplitude of the initial S-wave pulse in each record. The location of the 2008 seismogenic fault, as constrained by the near-fault strong motion data, is shown in Figure 7. 


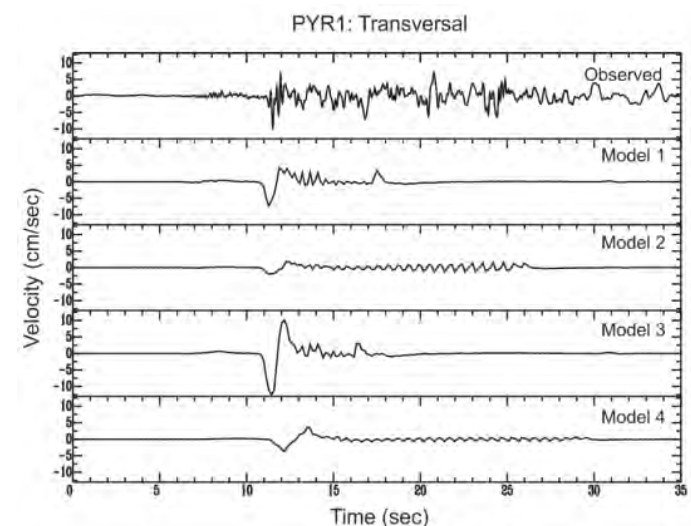

(a)

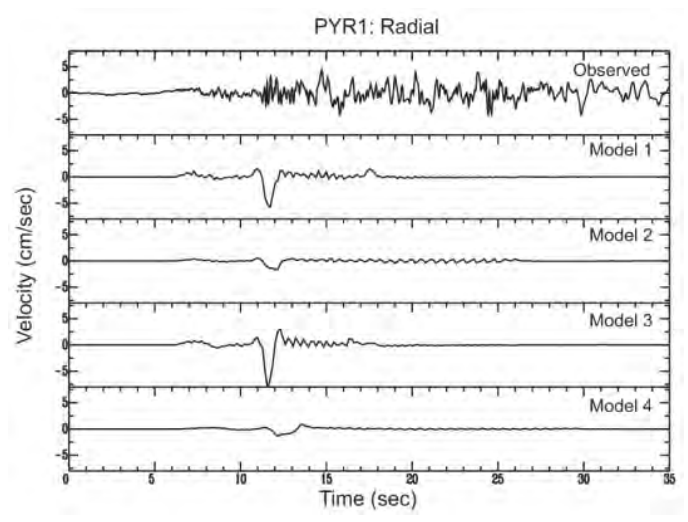

(b)

Figure 5 - a) Comparison of observed velocity at the transversal component of station PYR1 with synthetic waveforms based on four different fault models (Figure1, Table 2). All waveforms are high-pass filtered at $0.08 \mathrm{~Hz}$. b) Corresponding results for the radial component at station PYR1.
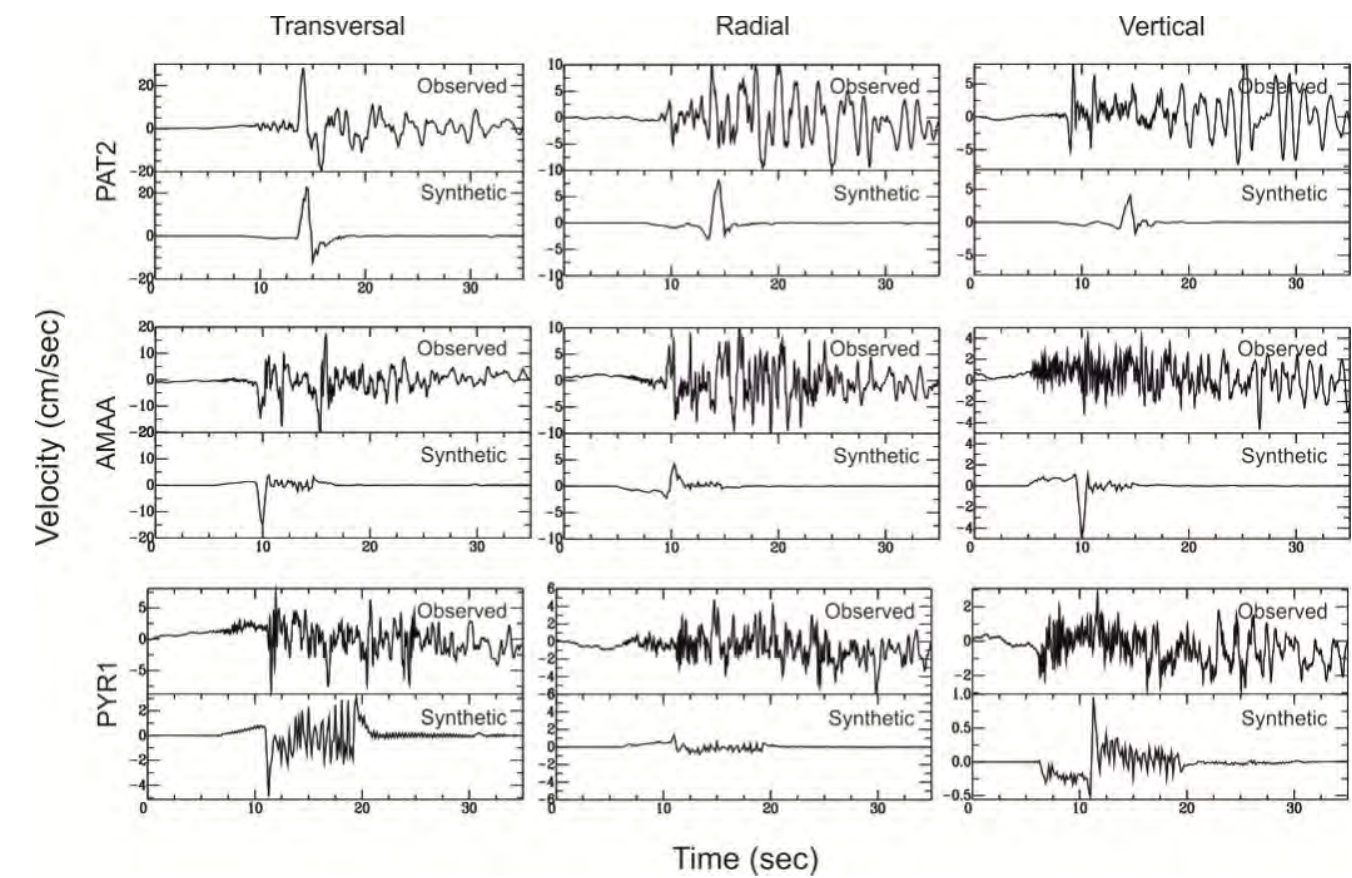

Figure 6 - Comparison of observed and synthetic velocity time histories from our preferred location of the 2008 seismogenic fault (Figure 7) at stations PAT2 (top), AMAA (center) and PYR1 (bottom).

\section{Conclusions - Discussion}

The 2008 Achaia-Ilia earthquake undoubtedly changed the so-far existing knowledge on the seismotectonic processes in the area of NW Peloponnese. It comprises the first dextral strike-slip earthquake of considerable magnitude that has been recorded from this part of Greece and provides further evidence for the possible existence of a second transform fault zone that accommodates the relative motion between Apulia and Aegean plates, similarly to the Cephalonia 
transform fault zone to the west. However, the imprints of the 2008 earthquake on the ground surface were limited and its role on the general seismotectonic setting can be revealed only through detailed studies of its source rupture characteristics.

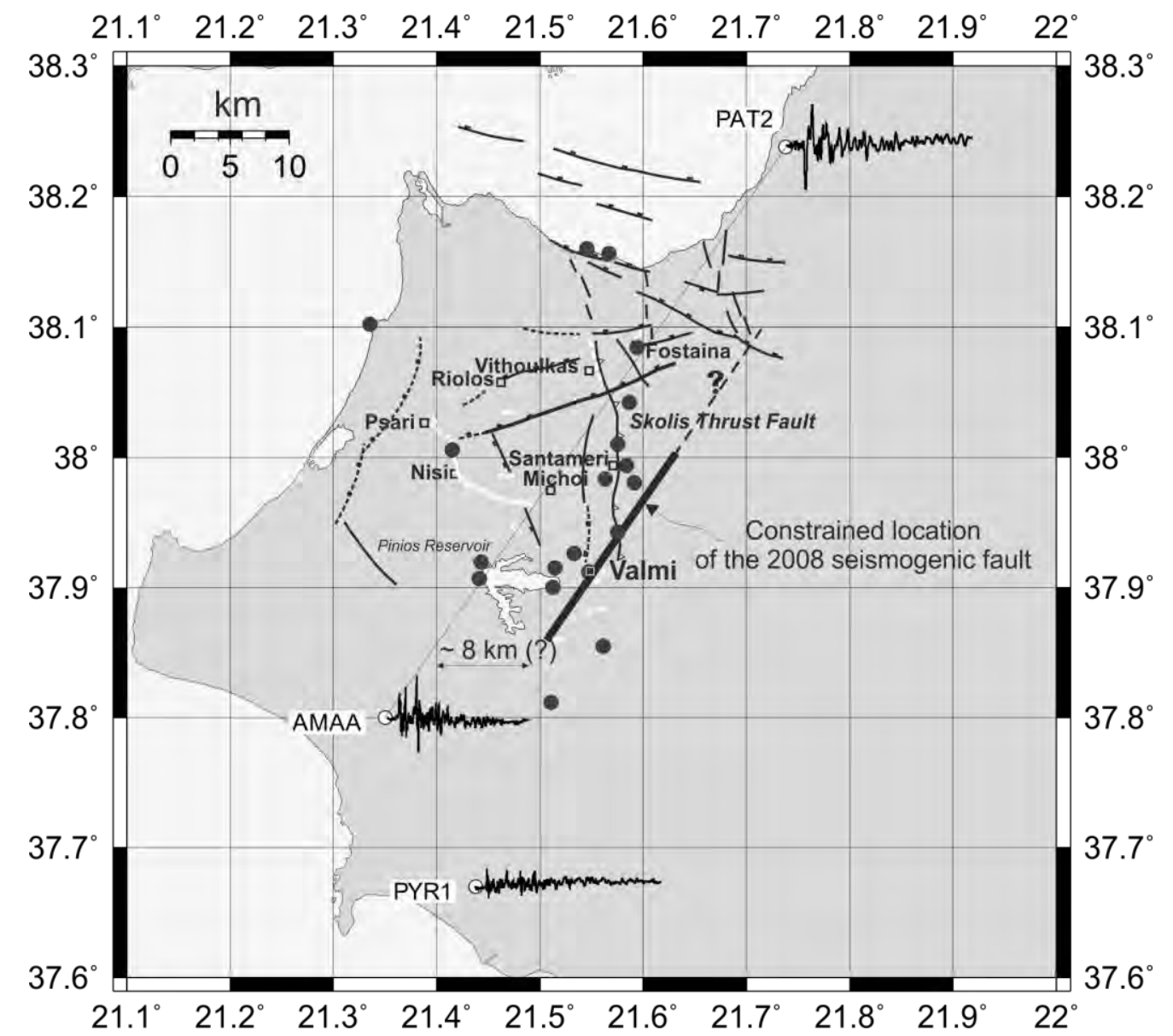

Figure 7 - Regional map showing the main tectonic structures of the 2008 epicentral area and 2008 surface ruptures (white lines) (reproduced from Figure 2 of Koukouvelas et al., 2010), and the herein constrained location (black thick line) of the 2008 seismogenic fault. Black dots denote areas of rock falls or liquefaction phenomena observed during the 2008 event (Margaris et al., 2010; Papadopoulos et al., 2010).

In this work we put additional constraints on the exact location of the 2008 seismogenic source through forward modeling near-fault strong motion data. We emphasized on correctly reproducing the theoretically expected sign and overall shape of long-period S-wave pulses. We conclude that the 2008 seismogenic fault (i.e, major moment release) is located to the east of stations AMAA and PAT2 and to the west of station PYR1. A preferred fault location is at approximately $8 \mathrm{~km}$ to the east of the imaginary line connecting stations AMAA and PAT2. This is very close to the limited surface ruptures mapped to the east of Pinios reservoir, close to the village of Valmi, by Koukouvelas et al. (2010), and, also close to the area where the majority of other ground failures i.e. rockfalls and liquefaction phenomena were observed. However, it must be clearly stated that in using the amplitude of the S-wave pulse to constrain the fault location, we assume the theoretically expected near-extinction of the radial displacement at near-nodal locations. However, this does not really occur in the real earth because crustal heterogeneities make the ray paths deviate from 
straight lines and thus the $\sim 8 \mathrm{~km}$ distance should be considered as an upper limit in our computations.

Although relative results are not presented herein, our analysis favors a fault that slipped at depths larger that $10-15 \mathrm{~km}$. This last finding is in accordance with the lack of surface expression of the fault (Koukouvelas et al., 2010) and the absent or limited permanent ground deformation in the broader epicentral area (Feng et al., 2010; Papadopoulos et al., 2010). Regarding the length of the rupture, we found that models of $16 \mathrm{~km}$ length sufficiently reproduce the salient features of the recorded motions. However, the overall duration of observations is better matched when the assumed length exceeds $30 \mathrm{~km}$. To better constrain the length of the ruptured area, more detailed modeling of the source, including inhomogeneous distribution of slip, is required.

\section{Acknowledgments}

This research was financially supported by EC-Project "International Transfer of Seismological Advanced Knowledge and Geophysical Research", a Transfer of Knowledge Marie-Curie action; MTKD-CT-2005-0296270. Z.R. acknowledges hosting in the facilities of ITSAK during the preparation of the present work. We thank Dr. Anna Serpetsidaki of the Seismological Laboratory of Patras University for providing raw data of locations used in Gallovic et al. (2009). Maps were produced using the GMT software (Wessel and Smith, 1998).

\section{References}

Bouchon M. 2003. A review of the discrete wavenumber method, Pure and Ap. Geophys., 160, 445-465.

Bouchon M. and Aki K. 1977. Discrete wave number representation of seismic source wave fields, Bull. Seism. Soc. Am., 67, 259-277.

Feng L., Newman A. V., Farmer G. T., Psimoulis P. and Stiros S.C. 2010. Energetic rupture, coseismic and post-seismic response of the $2008 \mathrm{Mw} 6.4$ Achaia-Elia earthquake in northwestern Peloponnese, Greece: an indicator of an immature transform fault zone, Geophys. J. Int., $183,103-110$.

Gallovic F., Zahradnik J., Krizova D., Plicka V., Sokos E., Serpetsidaki A. and Tselentis G.A. 2009. From earthquake cetroid to spatial-temporal rupture evolution: Mw6.3 Movri mountain earthquake, June 8, 2008, Greece, Geophys. Res. Lett., 36, L21310, doi: 10.1029/ 2009 GL040283.

Ganas A., Serpelloni E., Drakatos G., Kolligri M., Adamis I., Tsimi Ch. and Batsi E. 2009. The $\mathrm{M}_{\mathrm{w}}$ 6.4 SW-Achaia (Western Greece) earthquake of 8 June 2008: Seismological field, GPS observations, and stress modeling, J. Eq. Eng., 13(8), 1101-1124.

Gianopoulos D., Sokos E., Konstantinou K. I., Lois A. and Tselentis G.A. (2012). Temporal variation of shear-wave splitting parameters before and after the 2008 Movri Mountain earthquake in northwest Peloponnese (Greece), Annals of Geophys., 55(5), doi: 10.4401/ag5586.

Heaton T. H. 1990. Evidence for and implications of self-healing pulses of slip in earthquake rupture, Phys. of the Earth and Plan. Int., 64, 1-20.

Konstantinou K. I., Melis N. S., Lee S.-J., Evangelidis C. P. and Boukouras K. 2010. Rupture process and aftershocks relocation of the 8 June $2008 \mathrm{M}_{\mathrm{w}} 6.4$ earthquake in Northwest Peloponnese, Western Greece, Bull. Seism. Soc. Am. 99(6), 3374 - 3389, doi: 10.1785/ 0120080301.

Konstantinou K. I., Evangelidis C. P. and N. S. Melis, 2011. The 8 June $2008 \mathrm{M}_{\mathrm{w}} 6.4$ earthquake in northwest Peloponnese, western Greece: A case of fault reactivation in an overpressured lower crust?, Bull. Seism. Soc. Am. 101 (1), 438 - 445. 
Koukouvelas I. K., Kokkalas S. and Xypolias P. 2010. Surface deformation during the Mw6.4 (8 June 2008) Movri Mountain earthquake in the Peloponnese, and its implications for the seismotectonics of western Greece, Int. Geol. Rev. 52, $249-268$.

Margaris B., Athanasopoulos G., Mylonakis G., Papaioannou Ch., Klimis N., Theodulidis N., Savvaidis A., Efthymiadoy V. and Stewart J. P. 2010. The 8 June $2008 \mathrm{M}_{\mathrm{w}} 6.5$ Achaia-Elia, Greece earthquake: Source characteristics, ground motionsandground failure, Earthquake Spectra, 26(2), 399- 424.

Papadopoulos G. A., Karastathis V., Kontoes Ch., Charalampakis M., Fokaefs A. and Papoutsis I. 2010. Crustal deformation associated with east Mediterranean strike-slip earthquakes: The 8 June 2008 Movri (NW Peloponnese), Greece, earthquake (Mw6.4), Tectonophysics, 492, $201-212$.

Wessel P. and Smith W.H.F. 1998. New improved version of the Generic Mapping Tools released, EOS Trans. AGU, 79, 579.

Zahradnik J. and Gallovic F. 2010. Toward understanding slip-inversion uncertainty and artifacts, J. Geophs. Res., 115, B09310, pp. 16, doi: 10.1029/2010JB007414. 